\title{
Bispectral index in calves anesthetized with xylazine, midazolam, ketamine, isoflurane and subjected to continuous rate infusion of lidocaine ${ }^{1}$
}

\author{
Marcelo Augusto de Araújo ${ }^{\mathrm{I}}$, Carolina Aparecida Carlin Beloti ${ }^{\mathrm{II}}$, Maurício Deschk ${ }^{\mathrm{III}}$, André Moreira Martins Arruda ${ }^{\mathrm{IV}}$, Lu Shi \\ Cheng $^{\text {V }}$ Verônica Batista de Albuquerquev ${ }^{\text {VI }}$, Paulo Sergio Patto dos Santos ${ }^{\text {VII }}$ \\ DOI: http://dx.doi.org/10.1590/S0102-86502015001000009 \\ ${ }^{\mathrm{I}}$ Master, Veterinary Medical, Faculty of Veterinary Medicine and Animal Science, Federal University of Mato Grosso do Sul (UFMS), Campo Grande- \\ MS, Brazil. Conception, design, intellectual and scientific content of the study, technical procedures, manuscript writing.

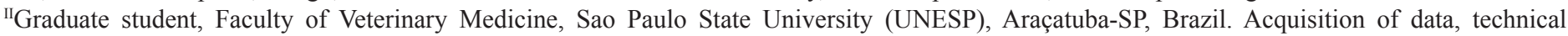 \\ procedures, manuscript writing.

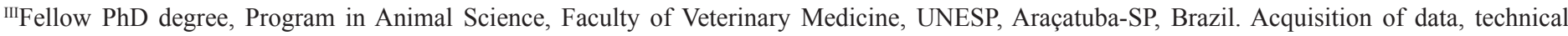 \\ procedures. \\ ${ }^{\mathrm{IV}}$ Felow Master degree, Department of Pharmacology, State University of Campinas (UNICAMP), Brazil. Acquisition of data, plasma lidocaine dosage. \\ v PhD, Galeno Research Unit, Campinas-SP, Brazil. Plasma lidocaine dosage, English language. \\ ${ }^{\mathrm{V}} \mathrm{PhD}$, Researcher FUNDECT/CNPq - C level, Department of Veterinary Medicine, Surgery and Anesthesiology, Faculty of Veterinary Medicine and \\ Animal Science, Federal University of Mato Grosso do Sul (UFMS), Campo Grande-MS, Brazil. Acquisition of data, technical procedures. \\ ${ }^{\mathrm{VII}} \mathrm{PhD}$, Assistant Professor, Department of Clinical, Surgery and Animal Reproduction, Faculty of Veterinary Medicine, UNESP, Araçatuba-SP, Brazil. \\ Conception of the study, statistical analysis, critical revision.
}

\section{ABSTRACT}

PURPOSE: To assess the bispectral index (BIS) and recovery in calves anesthetized with xylazine, midazolam, ketamine and isoflurane and subjected to CRI of lidocaine.

METHODS: Xilazine was administered followed by ketamine and midazolam, orotracheal intubation and maintenance on isoflurane using mechanical ventilation. Lidocaine ( $2 \mathrm{mg} \mathrm{kg}^{-1}$ bolus) or saline $(0.9 \%)$ was administered IV followed by a CRI (100 $\mu \mathrm{g} \mathrm{kg}^{-1}$ minute $\left.^{-1}\right)$ of lidocaine (L) or saline (C). Were recorded BIS, heart rate (HR), mean arterial pressure (MAP) and rectal temperature (RT) before administration of premedication (TB) and 15 minutes after (TX), before administering lidocaine (T0) and 20, 40, 60 and 80 minutes after the start of the CRI . Time do sternal recumbency (SRE) and standing (ST) and plasma lidocaine concentration also evaluated.

RESULTS: In both treatments BIS decreased significantly at all times compared to TB. TX was higher than the subsequent times. HR decreased from baseline at all times and decreased from T40 in L compared to C. SRE was higher in L compared to C.

CONCLUSIONS: Bispectral index values were consistent with the degree of hypnosis of the animals. Lidocaine did not potentiate isoflurane anesthesia assessed by BIS in unstimulated calves anesthetized with constant E'Iso. Lidocaine increased the time to sternal recumbency.

Key words: Anesthesia, inhalation. Intermittent Positive-Pressure Ventilation. Anesthesia Recovery Period. Chromatography. Cattle. 


\section{Introduction}

One of the main concerns of the anesthetist is the assessment of anesthetic depth. An inadequate plane of anesthesia in large animals may be associated with movements that may injure the animal, professionals that manipulate it or even the equipment around it. However, an excessive level of anesthesia increases the risk for complications such as cardiovascular depression and other adverse effects ${ }^{1}$.

Clinical assessment of the depth of anesthesia in animals requires the anesthetist to evaluate a variety of autonomic and motor reflexes, as well as changes in heart rate and arterial blood pressure. Although they are easily obtained, those clinical signs can be an imprecise method for judging the degree of central nervous system depression and analgesic requirement. Objective methods for assessing anesthetic depth and analgesic requirement that use processed electroencephalographic (EEG) data, such as the bispectral index (BIS), have been investigated ${ }^{2}$.

BIS derived from an algorithm which converts a single channel frontal EEG into an index of hypnosis that has been used $^{2}$. The BIS is computed in real time, and algorithms generate a number between 0 and 100, in which 0 indicates an isoelectric EEG and 100 represents the normal, conscious state ${ }^{3}$.

The use of the BIS has been investigated in several animal species including goats, horses, pigs, cats, dogs and alpacas ${ }^{1,4-8}$. The results of these studies are inconsistent, and in some studies a strong relationship between BIS and anesthetic depth has been found, in contrast to other studies. However, there are no reports that assess BIS in cattle.

It is believed that providing adequate analgesia before, during and after anesthesia and surgery minimizes patient stress and maximizes patient well-being ${ }^{9}$. Lidocaine is the most commonly used local anesthetic in veterinary medicine. It has been given intravenously (IV) during surgery as a supplement for general anesthesia ${ }^{10}$. Several studies have evaluated its effect on the MAC of inhaled anesthetics ${ }^{9,11-13}$ demonstrating a decrease in inhalation anesthetics requirements ${ }^{14,15}$ as well as intrinsic analgesic properties $^{16,17}$. The clinical changes induced by continuous rate infusion (CRI) of lidocaine have been reported in dogs, cats and horses ${ }^{18-21}$. However, the direct influence of lidocaine on the BIS has only been evaluated in $\operatorname{dogs}{ }^{8}$.

The purpose of the study was to evaluate the bispectral index in awake, sedated and anesthetized calves, as well as to determine the effects of continuous rate infusion of lidocaine at $100 \mu \mathrm{g} \mathrm{kg}^{-1}$ minute ${ }^{-1}$ on BIS and recovery of calves anesthetized with xylazine, midazolam, ketamine and maintained at a constant end tidal concentration (E'Iso) of isoflurane. The author's hypothetised that BIS would be consistent with degree of hypnosis of these animals and that CRI of lidocaine would not cause relevant changes on BIS and recovery from anesthesia.

\section{Methods}

Research approved by Institutional Animal Care and Use committee (protocol number 006409). Eight male Holstein calves aged $10 \pm 1$ months and weighing $114 \pm 11 \mathrm{~kg}$ were used in the study. All calves were considered healthy based on results of physical examination and complete blood count (CBC). Food was withheld for 24 hours and water for 12 hours before procedures.

Calves were anesthetized in two occasions in a cross-over design. The first four animals were treated with lidocaine (L) and the next four animals with saline (C). A washout period of at least 10 days was awaited between treatments, so that each calf could receive both treatments.

Before administration of pre-anesthetic medication, calves were restrained in left lateral recumbency and a 16-gauge catheter (Intracath; BD, Juiz de Fora-MG, Brazil) was inserted percutaneously into the right jugular vein for drug administration. Another 22-gauge catheter (Insyte; BD, Juiz de Fora-MG, Brazil) was inserted into the left auricular artery for invasive monitoring of arterial blood pressure.

Pre-anesthetic medication consisted of 0.05 mg kg-1 IV xylazine (20 mg mL-1Dopaser; Calier, Osasco, SP, Brazil) and 15 minutes after, induction of anesthesia was carried out with $2.0 \mathrm{mg} \mathrm{kg}^{-1}$ ketamine $\left(10 \mathrm{mg} \mathrm{mL}^{-1}\right.$ Vetaset; Fort Dodge, Campinas-SP, Brazil) and $0.1 \mathrm{mg} \mathrm{kg}^{-1}$ midazolam $(5 \mathrm{mg} \mathrm{mL}-1$ Dormire; Cristalia, Itapira-SP, Brazil) given intravenously. Immediately after induction, animals were intubated and positioned in right lateral recumbency. Subsequently, anesthesia was maintained with isoflurane (Isoforine; Cristália, Itapira-SP, Brazil) at constant E'Iso of $1.3 \%{ }^{22}$, using a calibrated vaporizer (HB, Sao Paulo-SP, Brazil) and rebreathing circuit system (Conquest Big; HB, Sao Paulo-SP, Brazil) with $15 \mathrm{~mL} \mathrm{~kg} \mathrm{~kg}^{-1}$ minute $^{-1}$ oxygen flow. End-tidal isoflurane concentration and end-tidal carbon dioxide tension $\left(\mathrm{PE}^{\prime} \mathrm{CO}_{2}\right)$ were monitored using a digital gas analyzer (Dixtal 2020; gas analyzer module, Dixtal, Manaus-AM, Brazil). Samples were continuously obtained from a sample line connected between the endotracheal tube and the breathing circuit. 
Intermittent positive pressure ventilation (IPPV) was set at the beginning of the procedure with a respiratory rate $\left(f_{R}\right)$ of six breaths minute ${ }^{-1}$ and peak inspiratory airway pressure of $15 \mathrm{cmH}_{2} \mathrm{O}$ using a mechanical ventilator (Conquest Big; HB, São Paulo, SP, Brazil). A 40-minute period was awaited prior to drug administration and data collection in order to guarantee equilibration of isoflurane.

Mean arterial pressure (MAP) was assessed through a 22-gauge catheter (which was placed in a branch of the left auricular artery and connected to a calibrated pressure transducer placed at the level of the sternum, which was zeroed prior to recordings). Heart rate (HR) was derived from the computerized electrocardiogram (DX-2020; Dixtal, Manaus-AM, Brazil) adjusted to lead II. Rectal temperature (RT) was measured using a digital thermometer (BD, Juiz de Fora-MG, Brazil).

After preparation period, calves in treatment $\mathrm{L}$ received $2.0 \mathrm{mg} \mathrm{kg}^{-1}$ IV lidocaine (20 mg mL ${ }^{-1}$, Xylestsin; Cristalia, ItapiraSP, Brazil) administered in 30 seconds followed by a $100 \mu \mathrm{g}$ $\mathrm{kg}^{-1}$ minute $^{-1} \mathrm{CRI}$ of lidocaine ${ }^{13}$. The lidocaine solution for CRI was prepared by adding $100 \mathrm{~mL}$ of lidocaine to $900 \mathrm{~mL}$ of $0.9 \%$ sodium chloride (Glicolabor, Ribeirao Preto-SP, Brazil), resulting in $2.0 \mathrm{mg} \mathrm{mL}^{-1}$ lidocaine in the final solution. For treatment $\mathrm{C}$ the same methodology was applied, however, $0.9 \%$ sodium chloride solution substituted lidocaine at the equivalent volume for each calf. Solutions were infused at $3.0 \mathrm{~mL} \mathrm{~kg}^{-1}$ hour $^{-1}$ through an infusion pump (ST55072, Samtronic, Sao Paulo-SP, Brazil).

Bispectral index was assessed by a monitor (DX2020; bispectral index module, Dixtal, Manaus-AM, Brazil) connected to the manufacturer designed BIS sensor (BIS Quatro Sensor, Aspect Medical System, Norwood, MA, USA). The head of each animal was shaved and cleansed with diethyl ether and the sensor was placed in frontal-temporal position, adapted from Campagnol et al. ${ }^{7}$. Electrode 1 was placed on the midline of the frontal bone region, above the eyes. Electrodes 2 and 4 were placed at an angle of $15^{\circ}$ to $30^{\circ}$ from the transverse plane. Electrode 3 was placed on the temporal bone region, cranial to the base of the left ear. The impedance of the electrodes was automatically checked by the BIS monitor and rejected if less than $7.5 \mathrm{k} \Omega$. Artifacts were identified by applying high and low frequency filters that were adjusted to 70 and $2 \mathrm{~Hz}$, respectively. The BIS number was hand recorded during 1 minute (one number per second) for each measure and the mean value was considered a single BIS number for that time point. The signal quality index (SQI), suppression ratio (SR) and electromyography (EMG) were also recorded in order to verify the reliability of BIS.
Anesthesia and CRI were discontinued after the last measurement and calves were allowed to recover. Time to sternal recumbency (SRE) and standing (ST) were evaluated.

For determining plasma concentrations of lidocaine, $5 \mathrm{~mL}$ blood samples were collected into lithium heparin tubes through the 16-gauge catheter inserted into the left jugular vein during anesthesia, and directly from the jugular vein after recovery. Samples were stored in a cooler with ice. At the end of each experiment, plasma was centrifuged for 10 minutes at 1000 $\mathrm{g}$ and frozen at $-80^{\circ} \mathrm{C}$ prior to analysis. Plasma concentrations of lidocaine were determined through liquid chromatography tandem mass spectrometry method using electrospray ionization ${ }^{23}$.

Variables BIS, HR, MAP and RT were recorded before premedication (TB), 15 minutes after premedication (TX), before lidocaine or sodium chloride $0.9 \%$ (T0) and every twenty minutes after the start of CRI (T20, T40 T60 and T80). $\mathrm{P}_{\mathrm{E}}{ }^{\prime} \mathrm{CO}_{2}$ was recorded from T0. In the L treatment group, blood samples for assessing plasma concentration of lidocaine were collected in T20, T40, T60, T80, ST, one hour after ST (T1h) and two hours after ST (T2h).

For Statistical analysis data are expressed as mean and standard deviation $(\mathrm{x} \pm \mathrm{SD})$. Shapiro-Wilk test was performed for attesting normal distribution (BioStat 5.8.4 professional; Analyst Soft, Chicago, USA). Normally distributed data (parametric) were analyzed through repeated measures analysis of variance (ANOVA), and Bonferroni multiple comparisons test if significance was detected. Data that failed normality test (non-parametric) were analyzed through Friedman test and Dunn posttest. Data concerning BIS were analyzed with One-way ANOVA and Bonferroni posttest for multiple comparisons between treatments and moments. Recovery was analyzed through Student's t test. Differences were considered significant when $\mathrm{p}<0.05$. Analyses were performed using computer software (Graphpad InStat 3; Graphpad Software Inc., San Diego, C.A, USA). Other data exported from the BIS monitor and logged were the SQI, EMG, SR and unfiltered EEG waveforms, but these were not analysed and used only to confirm that SQI and SR were within acceptable limits.

\section{Results}

In this study, BIS recordings in both groups has been always associated with $>90 \%$ signal quality index, suppression ratio of 0 and low electromyography activity. There were no significant differences between treatments concerning the BIS (Table 1). In both treatments BIS decreased significantly at all times from TB, and in TX it was significantly greater than subsequent measures. 
TABLE 1 - Mean \pm standard deviation of bispectral index in eight calves anesthetized with xylazine, midazolam, ketamine and isoflurane and subjected to continuous rate infusion of lidocaine at $100 \mu \mathrm{g} \mathrm{kg}^{-1}$ minute $^{-1}$ (treatment L) or $0.9 \%$ sodium chloride (treatment C).

\begin{tabular}{lccccccc}
\hline & \multicolumn{7}{c}{ Time } \\
\cline { 2 - 8 } Treatment & Baseline & Xylazine & T0 & T20 & T40 & T60 & T80 \\
C & $96 \pm 4^{\mathrm{a}}$ & $76 \pm 8^{\mathrm{b}}$ & $35 \pm$ & $36 \pm$ & $38 \pm$ & $38 \pm$ & $39 \pm$ \\
& & & $6^{\mathrm{c}}$ & $3^{\mathrm{c}}$ & $7^{\mathrm{c}}$ & $9^{\mathrm{c}}$ & $5^{\mathrm{c}}$ \\
$\mathrm{L}$ & $93 \pm 3^{\mathrm{a}}$ & $74 \pm 10^{\mathrm{b}}$ & $39 \pm$ & $35 \pm$ & $35 \pm$ & $36 \pm$ & $36 \pm$ \\
& & & $5^{\mathrm{c}}$ & $3^{\mathrm{c}}$ & $2^{\mathrm{c}}$ & $3^{\mathrm{c}}$ & $2^{\mathrm{c}}$ \\
\hline
\end{tabular}

In both treatments, HR decreased significantly from baseline at all times (Table 2). After administration of CRI of lidocaine, values were significantly lower at T40, T60 and T80 in $\mathrm{L}$ compared to $\mathrm{C}$. There was no significant difference between treatments in regard to MAP. In both treatments MAP was lower in $\mathrm{T} 0$ compared to $\mathrm{TB}$, and in treatment $\mathrm{C}$ MAP values were also lower at T0 compared to T40, T60 and T80.

There was no difference among time points within each treatment and between treatments for $\mathrm{PE}^{\prime} \mathrm{CO}_{2}$ and RT (Table 2).

TABLE 2 - Mean \pm standard deviation of heart rate (HR), mean arterial pressure (MAP), end-tidal carbon dioxide tension $\left(\mathrm{PE}^{\prime} \mathrm{CO}_{2}\right)$ and rectal temperature (RT) of eight calves anesthetized with xylazine, midazolam, ketamine and isoflurane and subjected to continuous rate infusion of lidocaine at $100 \mu \mathrm{g} \mathrm{kg}^{-1}$ minute (treatment L) or $0.9 \%$ sodium chloride (treatment C).

\begin{tabular}{|c|c|c|c|c|c|c|c|c|}
\hline \multirow{2}{*}{ Variable } & \multirow{2}{*}{ Treatment } & \multicolumn{7}{|c|}{ Time } \\
\hline & & TB & TX & T0 & T20 & T40 & T60 & T80 \\
\hline HR & C & $\begin{array}{c}70 \pm \\
8^{\mathrm{a}}\end{array}$ & $\begin{array}{c}56 \pm \\
4^{\mathrm{b}}\end{array}$ & $\begin{array}{c}56 \pm \\
2^{\mathrm{b}}\end{array}$ & $\begin{array}{c}60 \pm \\
7^{\mathrm{b}}\end{array}$ & $\begin{array}{l}61 \pm \\
9^{\text {Aab }}\end{array}$ & $\begin{array}{l}62 \pm \\
7^{\text {Aab }}\end{array}$ & $\begin{array}{l}62 \pm \\
7^{\text {Aab }}\end{array}$ \\
\hline $\begin{array}{l}\text { (beats } \\
\text { minute }^{-1}\end{array}$ & $\mathbf{L}$ & $\begin{array}{c}71 \pm \\
7^{\mathrm{a}}\end{array}$ & $\begin{array}{c}55 \pm \\
7^{\mathrm{b}}\end{array}$ & $\begin{array}{c}57 \pm \\
3^{b}\end{array}$ & $\begin{array}{c}50 \pm \\
4^{\mathrm{b}}\end{array}$ & $\begin{array}{c}51 \pm \\
3^{\mathrm{Bb}}\end{array}$ & $\begin{array}{c}51 \pm \\
5^{\mathrm{Bb}}\end{array}$ & $\begin{array}{c}51 \pm \\
9^{\mathrm{Bb}}\end{array}$ \\
\hline MAP & $\mathrm{C}$ & $\begin{array}{c}115 \\
\pm \\
11^{\mathrm{a}}\end{array}$ & $\begin{array}{l}98 \pm \\
18^{\text {ab }}\end{array}$ & $\begin{array}{c}75 \pm \\
19^{\mathrm{b}}\end{array}$ & $\begin{array}{l}95 \pm \\
25^{\text {ab }}\end{array}$ & $\begin{array}{c}101 \\
\pm \\
23^{\mathrm{a}}\end{array}$ & $\begin{array}{c}105 \\
\pm \\
20^{\mathrm{a}}\end{array}$ & $\begin{array}{c}107 \\
\pm \\
17^{\mathrm{a}}\end{array}$ \\
\hline $\begin{array}{c}(\mathrm{mm} \\
\mathrm{Hg})\end{array}$ & $\mathbf{L}$ & $\begin{array}{l}112 \\
\pm 8^{\mathrm{a}}\end{array}$ & $\begin{array}{r}96 \pm \\
14^{\mathrm{ab}}\end{array}$ & $\begin{array}{c}82 \pm \\
25^{\mathrm{b}}\end{array}$ & $\begin{array}{l}90 \pm \\
20^{\text {ab }}\end{array}$ & $\begin{array}{l}90 \pm \\
16^{\mathrm{ab}}\end{array}$ & $\begin{array}{c}89 \pm \\
9^{\mathrm{ab}}\end{array}$ & $\begin{array}{l}93 \pm \\
11^{\text {ab }}\end{array}$ \\
\hline $\mathrm{P}_{\mathrm{E}}{ }^{\prime} \mathrm{CO}_{2}$ & C & nd & nd & $\begin{array}{r}43 \\
\pm 7\end{array}$ & $\begin{array}{l}43 \\
\pm 9\end{array}$ & $\begin{array}{l}45 \\
\pm 8\end{array}$ & $\begin{array}{l}45 \\
\pm 8\end{array}$ & $\begin{array}{l}44 \\
\pm 8\end{array}$ \\
\hline $\begin{array}{l}(\mathrm{mm} \\
\mathrm{Hg})\end{array}$ & $\mathbf{L}$ & nd & nd & $\begin{array}{l}39 \\
\pm 7\end{array}$ & $\begin{array}{r}40 \\
\pm 9\end{array}$ & $\begin{array}{l}42 \\
\pm 8\end{array}$ & $\begin{array}{l}42 \\
\pm 9\end{array}$ & $\begin{array}{c}43 \pm \\
10\end{array}$ \\
\hline RT & C & $\begin{array}{c}38.5 \\
\pm \\
0.5\end{array}$ & $\begin{array}{c}38.8 \\
\pm \\
0.5\end{array}$ & $\begin{array}{c}38.1 \\
\pm \\
0.7\end{array}$ & $\begin{array}{c}38.0 \\
\pm \\
0.9\end{array}$ & $\begin{array}{c}37.9 \\
\pm \\
0.8\end{array}$ & $\begin{array}{c}38.0 \\
\pm \\
0.9\end{array}$ & $\begin{array}{c}38.0 \\
\pm \\
1.0\end{array}$ \\
\hline$\left({ }^{\circ} \mathrm{C}\right)$ & $\mathbf{L}$ & $\begin{array}{c}38.7 \\
\pm \\
0.6\end{array}$ & $\begin{array}{c}39,0 \\
\pm \\
0.5\end{array}$ & $\begin{array}{c}38.3 \\
\pm \\
0.9\end{array}$ & $\begin{array}{c}38.4 \\
\pm \\
0.9\end{array}$ & $\begin{array}{c}38.3 \\
\pm \\
0.7\end{array}$ & $\begin{array}{c}38.3 \\
\pm \\
0.8\end{array}$ & $\begin{array}{c}38.4 \\
\pm \\
1.0\end{array}$ \\
\hline
\end{tabular}

nd $=$ not done
SRE was significantly greater in treatment L compared to C. There was no significant difference in ST between treatments (Table 3).

TABLE 3 - Mean \pm standard deviation of time to achieve sternal recumbency and standing position of eight calves anesthetized with xylazine, midazolam, ketamine and isoflurane and subjected to continuous rate infusion of lidocaine at $100 \mu \mathrm{g}$ $\mathrm{kg}^{-1}$ minute $^{-1}$ (treatment L) or $0.9 \%$ sodium chloride (treatment C).

\begin{tabular}{lcc}
\hline \multirow{2}{*}{ Recovery } & \multicolumn{2}{c}{ Time (minutes) } \\
\cline { 2 - 3 } Sternal recumbency & Treatment $\mathbf{C}$ & Treatment $\mathbf{L}$ \\
\hline Standing position & $16 \pm 4^{\mathrm{A}}$ & $23 \pm 8^{\mathrm{B}}$ \\
\hline
\end{tabular}

The plasma concentration of lidocaine ranged from 1.85 to $2.06 \mu \mathrm{g} \mathrm{mL}^{-1}$ during CRI of lidocaine, and decreased to $1.34 \mu \mathrm{g}$ $\mathrm{mL}^{-1}$ in the ST, $0.23 \mu \mathrm{g} \mathrm{mL}^{-1}$ in the T1h and $0.07 \mu \mathrm{g} \mathrm{mL}^{-1}$ in the T2h.

\section{Discussion}

The use of a CRI of lidocaine at $100 \mu \mathrm{g} \mathrm{kg}^{-1}$ minute ${ }^{-1}$ was based on one previous study using lidocaine in ruminants ${ }^{13}$.

The BIS values observed when calves were awake, sedated and anaesthetized were compatible with the changes in degree of hypnosis of the animals, since BIS is inversely related to depth of anesthesia ${ }^{24}$.

BIS is usually found above 90 in unmedicated, awake humans and steadily decreases as the proportion of sedation and hypnosis increases. Values ranging from 40 to 60 are generally associated to surgical anesthesia (unconscious patient), whereas values $>60$ are considered to represent increasing levels of consciousness $^{25}$. Previous studies have evaluated BIS in horses ${ }^{1}$, cats $^{26}$ and $\operatorname{dog} s^{7}$ anesthetized with isoflurane in concentrations close to $1 \mathrm{MAC}$, and have reported 45 as the lower mean BIS value found. Unlike these findings, in our study, the mean values of BIS during maintenance of anesthesia with 1 MAC isoflurane always remained below 40, which demonstrates that in this species BIS values in unconscious patients are probably lower than those reported in other species. Thus, further research is necessary in order to evaluate the correlation between hypnosis and BIS in cattle.

Vesal et al. ${ }^{10}$ have reported that CRI of lidocaine promoted reduction of anesthetic requirement of isoflurane in $17 \%$. However this has not been demonstrated by the BIS in our study, since CRI of lidocaine promoted only a slight decrease in BIS (not significant). According to Hans et al. ${ }^{27}$ this could not be evidenced by the BIS because the effects of IV lidocaine are related to anti-nociceptive action 
rather than hypnosis. The results of several studies ${ }^{4,6,26}$ also suggested that the dynamic changes in BIS following noxious stimuli have greater correlation with the level of hypnosis and depth of anesthesia compared to BIS values recorded in the absence of noxious stimuli.

CRI of lidocaine has significantly decreased HR. Similarly, Pypendop and Ilkiw ${ }^{19}$ have observed this decrease in cats anesthetized with isoflurane, which received a CRI of lidocaine at predetermined rates to achieve plasma concentrations of 3 to $11 \mathrm{ng} \mathrm{mL}{ }^{-1}$. Studies in horses ${ }^{21}, \operatorname{dogs}^{18}$ and bovines ${ }^{10}$ have demonstrated no changes in HR in response to CRI of lidocaine. Several studies suggest that IV lidocaine can promote changes in HR by interacting with sodium channels and by inhibiting cellular calcium influx, thereby promoting changes in depolarization and conduction speed in myocardial Purkinje fibers ${ }^{28,29}$.

CRI of lidocaine increased time to recovery for both SRE and ST, but significant difference between treatments was only observed in SRE. Dzikiti et al. ${ }^{11}$ have anesthetized horses with CRI of lidocaine and have also reported slightly prolonged recovery. On the other hand, Valverde et $a l^{30}$ have reported that CRI of lidocaine has a negative effect on recovery from anesthesia in horses because it increases the degree of ataxia. This has not been observed in our study, where animals of both treatments have showed the same pattern of recovery, with only a slight increase in time. However it is important to note that bovines normally recover well from general anesthesia and rarely attempt to stand up precociously, remaining in sternal recumbency until they are fully able to stand. Similarly Vesal et al. ${ }^{10}$ have not observed adverse effects in isoflurane-anesthetized calves that received CRI of lidocaine and have reported that all calves recovered uneventfully.

During CRI of lidocaine, plasma lidocaine concentration values obtained in this study during CRI were similar to those reported by Doherty et al. ${ }^{13}$ in goats subjected to the same CRI of lidocaine $\left(1.6 \mu \mathrm{g} \mathrm{mL}^{-1}\right)$. However, $50 \mu \mathrm{g} \mathrm{kg}^{-1} \mathrm{~min}^{-1}$ lidocaine CRI in dogs resulted in plasma concentrations of approximately $1.5 \mu \mathrm{g}$ $\mathrm{mL}^{-1} 15$ and values between 3.0 and $4.0 \mu \mathrm{g} \mathrm{mL}^{-1}$ have been reported for the same infusion rate in isoflurane-anesthetized horses ${ }^{11,31}$.

According to Doherty et $a l .{ }^{13}$ the lower plasma concentration of lidocaine in goats may be due to a faster clearance. The reason for the lower plasma concentration of lidocaine in this study could not be determined, as it would require the investigation of lidocaine kinetics in bovines.

\section{Conclusions}

Bispectral index was consistent with the degree of hypnosis of calves and infusion of lidocaine at the studied rate did not alter BIS values in unstimulated calves anesthetized with a constant E'Iso of $1.3 \%$. Furthermore, CRI of lidocaine increased the time to sternal recumbency.

\section{References}

1. Haga HA, Dolvik NI. Evaluation of the bispectral index as an indicator of degree of central nervous system depression in isoflurane-anesthetizes horses. Am J Vet Res. 2002 Mar;63(3):43842. doi: 10.2460/ajvr.2002.63.438.

2. Henao-Guerreno PN, McMurphy R, Kukanich B, Hodgson DS. Effect of morphine on the bispectral index during isoflurane anesthesia in dogs. Vet Anaesth Analg. 2009 Mar;36(2):133-43. doi: 10.1111/j.1467-2995.2008.00440.x.

3. Rosow C, Manberg PJ. Bispectral index monitoring. Anesthesiol Clin North Am. 2001 Dec;19(4):947-66.

4. Antognini JF, Wang XW, Cartens, E. Isoflurane anaesthetic depth in goats monitored using the bispectral index of the electroencephalogram. Vet Res Commun. 2000 Sep;24(6):361-70.

5. Martin-Cancho M, Lima JR, Luis L, Crisóstomo V, Ezquerra LJ, Carrasco MS, Usón-Gargallo J. Bispectral index, spectral edge frequency $95 \%$, and median frequency recorded for various concentration of isoflurane and sevoflurane in pigs. Am J Vet Res. 2003 Jul;64(7):866-73. doi: 10.2460/ajvr.2003.64.866.

6. March PA, Muir WW. Use of the bispectral index as a monitor of anesthetic depth in cats anesthetized with isoflurane. Am J Vet Res. 2003 Dec;64(12):1534-41. doi: 10.2460/ajvr.2003.64.1534.

7. Campagnol D, Teixeira Neto FJ, Monteiro ER, Beier LS, Aguiar AJA. Use of bispectral index to monitor depth of anesthesia in isoflurane-anesthetized dogs. Am J Vet Res. 2007 Dec;68(12):13007. doi: 10.2460/ajvr.68.12.1300.

8. Garcia-Pereira FL, Greene AS, keegan RD, McEwen MM, Tibary A. Effects of intravenous butorphanol on cardiopulmonary function in isoflurane-anesthetized alpacas. Vet Anesth Analg. 2007 Jul;34(4):269-74. doi: 10.1111/j.1467-2995.2006.00325.x.

9. Muir WW, Wiese AJ, March PA. Effects of morphine, lidocaine, ketamine, and morphine-lidocaine-ketamine drug combination on minimum alveolar concentration in dogs anesthetized with isoflurane. Am J Vet Res. 2003 Sep;64(9):1155-60. doi: 10.2460/ ajvr.2003.64.115.

10. Vesal N, Spadavecchia C, Steiner A, Kirscher F, Levionnois OL. Evaluation of the isoflurane-sparing effects of lidocaine infusion during umbilical surgery in calves. Vet Anaest Analg. 2011 Sep;38(5):451-60. doi: 10.1111/j.1467-2995.2011.00636.x.

11. Dzikiti TB, Hellebrekers P, Van Dijk P. Effects of intravenous lidocaine on isoflurane concentration, physiological parameters, metabolic parameters and stress-related hormones in horses undergoing surgery. J Vet Med A. 2003 May;50(4):190-5.

12. Pypendop BH, Ilkiw JE. The effects of intravenous lidocaine administration on the minimum alveolar concentration of isoflurane in cats. Anesth Analg. 2005 Jan;100(1):97-101. doi: 10.1213/01. ANE.0000139350.88158.38.

13. Doherty T, Redua MA, Queiroz-Castro P, Egger C, Cox SK, Rohrbach BW. Effect of intravenous lidocaine and ketamine on the minimum alveolar concentration of isoflurane in goats. Vet Anaest Analg. 2007 Mar;34(2):125-31. doi: 10.1111/j.14672995.2006.00301.x.

14. Doherty TJ, Frazier DL. Effect of intravenous lidocaine on halothane minimum alveolar concentration in ponies. Equine Vet J. 1998 Jul;30(4):300-3. doi: 10.1111/j.2042-3306.1998.tb04101.x.

15. Valverde A, Doherty TJ, Hérnandez J, Davies W. Effect of lidocaine on the minimum alveolar concentration of isoflurane in dogs. 
Vet Anaest Analg. 2004 Oct;31(4):264-74. doi: 10.1111/j.14672995.2004.00165.x.

16. Murrel JC, White KL, Johnson CB, Taylor PM, Doherty TJ, Waterman-Pearson AE. Investigation of the EEG effects of intravenous lidocaine during halothane anaesthesia in ponies. Vet Anaest Analg. 2005 Jul;32(4):212-21. doi: 10.1111/j.14672995.2005.00201.x.

17. Robertson SA, Sanches LC, Merrit AM, Doherty TJ. Effect of systemic lidocaine on visceral and somatic nociception in conscious horses. Equine Vet J. 2005 Mar;37(2):122-7. doi: 10.2746/0425164054223723.

18. Moraes AN, Dyson DH, O'Grady MR, McDonell WN, Holmberg DL. Plasma concentration and cardiovascular influence of lidocaine infusions during isoflurane anesthesia in healthy dogs and dogs with subaortic stenosis. Vet Surg. 1998 Sep-Oct 27(5):486-97. doi: 10.1111/j.1532-950X.1998.tb00161.x.

19. Pypendop BH, Ilkiw JE. Assessment of the hemodynamic effects of lidocaine administered IV in isoflurane-anesthetized cats. Am J Vet Res. 2005 Apr;66(4):661-8. doi: 10.2460/ajvr.2005.66.661.

20. Ringer SK, Kalchofner K, Boller J, Fürst A, BettschartWolfensberger R. A clinical comparison of two anaesthetic protocols using lidocaine or medetomidine in horses. Vet. Anaesth. Analg. 2007 Jul;34(4):257-68. doi: 10.1111/j.1467-2995.2006.00321.x.

21. Valverde A, Rickey E, Sinclair M, Rioja E, Pedernera J, Hathway A, Cruz A. Comparison of cardiovascular function and quality of recovery in isoflurane-anaesthetised horses administered a constant rate infusion of lidocaine or lidocaine and medetomidine during elective surgery. Equine Vet. J. 2010 Apr;42(3):192-9. doi: 10.1111/j.2042-3306.2010.00027.x.

22. Cantalapietra AG, Villanueva B, Pereira JL. Anaesthetic potency of isoflurane in cattle: Determination of the minimum alveolar concentration. Vet Anaesth Analg. 2000 Jan;27(1):22-6. doi: 10.1046/j.1467-2995.2000.00002.x.

23. Mendes FD, Chen LS, Borges A, Babadópulos T, Ilha JO, Alkharfy KM, Mendes GD, De Nucci G. Ciprofibrate quantification in human plasma by high performance liquid chromatography coupled with electrospray tandem mass spectrometry for pharmacokinetic studies. J Chromatogr B Analyt Technol Biomed Life Sci. 2012 Aug;15;879(24):2361-8. doi: 10.1016/j.jchromb.2011.05.055.

24. Johansen JW, Sebel PS. Development and clinical application of electroencephalographic bispectrum monitoring. Anesthesiology. 2000 Nov;93(5):1336-44.

25. Kissin I. Depth of anesthesia and bispectral index monitoring. Anesth Analg. 2000 May;90(5):1114-7. doi: 10.1097/00000539200005000-00021.

26. MarchPA,MuirWW.Bispectralanalysis of the electroencephalogram: a review of its development and use in anesthesia. Vet Anaest Analg. 2005 Sep;32(5):241-55. doi: 10.1111/j.1467-2995.2005.00221.x.

27. Hans GA, Lauwick SM, Kaba A, Bonhomme V, Struys MM, Hans PC, Lamy ML, Joris JL. Intravenous lidocaine infusion reduces bispectral index-guided requirements of propofol only during surgical stimulation. Br J Anaesth. 2010 Oct;105(4):471-9. doi: $10.1093 / \mathrm{bja} / \mathrm{aeq} 189$.

28. Wilson RA, Soel LK, Beztarosti K, Lamers JM, Verdouw PD. Negative inotropy of lidocaine: possible biochemical mechanisms. Eur Heart J. 1993 Feb;14(2):284-9. doi: 10.1093/eurheartj/14.2.284.

29. Pankucsi C, Varrô A, Nánási PP. Three distinct components of the negative inotropic action of lidocaine in dog Purkinje fiber. Gen Pharmacol. 1996 Jan;27(1):69-71. doi: 10.1016/03063623(95)00089-5.

30. Valverde A, Gunkelt C, Doherty TJ, Giguère S, Pollak AS. Effect of a constant rate infusion of lidocaine on the quality of recovery from sevoflurane or isoflurane general anaesthesia in horses. Equine Vet
J. 2005 Nov;37(6):559-64. doi: 10.2746/042516405775314772.

31. Feary DJ, Mama KR, Wagner EA, Thomasy S. Influence of general anesthesia on pharmacokinetics of intravenous lidocaine infusion in horses. Am J Vet Res. 2005 Apr;66(4):574-80. doi: 10.2460/ ajvr.2005.66.574.

\section{Correspondence:}

Paulo Sergio Patto dos Santos

Rua Clovis Pestana, 793

16050-680 Araçatuba - SP Brasil

Tel.: (55 18)3211-1433

patto@fmva.unesp.br

Received: Sep 19, 2014

Review: Nov 17, 2014

Accepted: Dec 18, 2014

Conflict of interest: none

Financial source: Sao Paulo Research Foundation (FAPESP): scholarship (process number 07555-0) and financial support (process number 088796).

${ }^{1}$ Research performed at Department of Clinical, Surgery and Animal Reproduction, Faculty of Veterinary Medicine, Sao Paulo State University (UNESP), Araçatuba-SP, Brazil. 